\title{
Research as a Cornerstone of Quality Assurance in University Education with specific Reference to Uganda Martyrs University
}

\author{
Pontian G. Okoth ${ }^{1}$
}

(C) Uganda Martyrs University

\begin{abstract}
This paper discusses the nexus between research and quality assurance in contemporary higher education, with specific reference to Uganda Martyrs University. Starting with discussion of the concept of research-touching on the conceptualization of what constitutes research; disambiguation of key terms and concepts in research; and discussion of major research paradigms and designs - the paper discusses the place of research as an aspect of quality assurance in university education. Thereafter, it articulates a case for research in higher education and discusses the state of research, quality assurance and the meeting points of the two at Uganda Martyrs University.
\end{abstract}

Keywords $\cdot$ Research $\cdot$ Quality assurance $\cdot$ Higher education

\section{Introduction}

The term research is of French origin (from recherché) and means a "careful search or investigation, systematic investigation towards increasing the sum of Knowledge" (Murty 1995:1). Hence, research deals with the procedural facets of the careful search and investigation in a disciplinary context within the realms of the humanities, social sciences and science.

Research, in our view, is the major function of a university worth its salt. The other functions of the university being teaching, touching base with the community and publishing which all have to be anchored on research, and quality research at that; research that is supposed to positively transform society by solving its problems rather than research for its sake. How such research is supposed to be conducted, constitutes the problem in this paper which consists of four sections. The first section deals with issues of method versus methodology. The second section deals with some approaches to research. The third section deals with issues of quality assurance in research. Conclusions wrap up the paper. The aim is not to reinvent the wheel but rather to revisit it with the view to

\footnotetext{
${ }^{1}$ Masinde Muliro University of Science and Technology. E-mail: pontianokoth@yahoo.com
} 
providing an opportunity for reflections and re-examination of theoretical insights which can aid in improving the quality of research. Another aim is to target beginning researchers with the view to initiating them in the rigor of research as a scholarly enterprise.

\section{Method versus Methodology}

It is instructive to observe that although those who teach research methods commonly use the terms "method" and "methodology" interchangeably, the terms are not equivalent. The term method denotes a scientific procedure; it is the specification of the steps to be taken in order to achieve a desired end (data collection and analysis).

"Methodology", on the other hand, is a concept of the next highest order; it stands above (or "meta") to method because it is not a method but, instead is about methods. Methodology refers to the system of theory, logical principles, and philosophical particular methods to gather and analyze data. And, just as there are different methods available to the researcher, so are there different methodologies available to guide the process of inquiry from inception (problem identification and formulation) through research design (selection and application of methods) to completion (conclusion and policy recommendations) (Retcliffe 1983:147-167).

At a fundamental level, all approaches to scientific inquiry are based on assumptions (articles of faith) about how the world "works". Such assumptions are inevitable because not everything of importance can be known with complete assurance or perfect certainty before action can be taken. The approach to research that currently dominates the thinking and practice of the scientific community based on several fundamental assumptions, one of which is that a universal, objective reality exists "out there" can be apprehended in an equally scientific method. Consistent with this fundamental assumption is the view that the practice of science is or can be value - free or value-neutral. For example, that "ethical neutrality ... means that the scientist in his [sic] professional capacity does not take sides on issues of moral or ethical significance ... As a scientist he [sic]is interested not in what is right or wrong or good or evil, but only in what is true or false" (Mitroff and Sagasti 1973:117; Rakitov 1989:14).

But another competing conceptualization of science is emerging, one that is making itself felt across all the disciplines. The emergent paradigm is based on very different fundamental assumptions, one of which is that all systems including systems of scientific inquiry, are purposeful and, therefore, necessarily value laden or normative. This approach to science assumes that researchers inevitably take sides (consciously or unconsciously) on issues of normal and ethical significance, and that they cannot be interested in and be influenced by what they feel is good or bad, right or wrong, and what should or ought to be in their quest for what is true or false. From the paradigmatic perspective, all science is qualitative at a fundamental level. For it recognizes that since all science is ultimately based on assumptions, or articles of faith, there are no "givens", but only "takens" (i.e. assumptions that are taken as given). Said another way, research problem cannot be separated meaningfully from their human components and they are thus inherently matters of values and ideology. Hence even the point of view that there can be no point of view (i.e. objectivity) is still a point of view. It is this paradigmatic perspective on research that constitutes the subject matter of any research method and methodology (Schwartz and Ogilvy 1979: 60). 
Since a fundamental assumption is that all research is inherently value laden including that undertaken within the framework of the allegedly value neutral "scientific method" it is imperative to emphasize the ethical dimensions of scientific inquiry - how to identify value biases in the work of others, how to deal with it on one's own research, and what its implications are for the professional practitioner. The issue is how to think about it, and how to think about it from the perspective of a very different paradigm from that which currently holds sway over the scientific community (Hall 1977:23).

While some methods unique to this to this paradigmatic perspective can be applied, this is not a "methods" submission, but instead, one on methodology. It is intended to provide a framework for thinking about research that will allow one to match the various methods of scientific inquiry usefully to the classes of problems and contexts to which they are relevant and applicable. This exposure to research is not designed to restrict the researcher to a narrow set of methods or approaches; nor does it require the researcher to reject "old" methods in favour of "new" methods. What it does require is the willingness to open oneself up to a new worldview, one that necessitates active involvement in a major reformulation of one's thinking about an approach to scientific research in general, and about the nature of relationships among theory, (method, data, purpose, values and assumptions in particular (Mitroff and Kilman 1981:43). At this juncture, some details regarding approaches to research are provided.

\section{Approaches to Research}

It is not possible to carry out a worthwhile investigation without having detailed knowledge of the various approaches to or styles of research. But a study of different approaches will give insight into different ways of planning an investigation, and, will also enhance understanding of the literature. One of the problems of reading about research reports and reading research reports is the terminology. Researchers use terms and occasionally jargon that may be incomprehensible to lay people and even other disciplinarians. It is the same in any field, where a specialized language develops to ease communication among professionals. So, before considering the various stages of planning and conducting investigations, it is instructive to consider the main features of certain well established and well -reported styles of research (Bell 2010:5).

Different styles, traditions or approaches use different methods of collecting data. However, no approach prescribes or automatically rejects any particular method. Quantitative researchers collect facts and study the relationship of one set of facts to another. They use "numerical data and, typically ... structured and predetermined research questions, conceptual frameworks and designs' (Punch 2005:28). They, therefore, use techniques that are likely to produce quantified and, if possible, generalizable conclusions. Researchers adopting a quantitative perspective are more concerned with understanding individuals' perceptions of the world. They doubt whether social 'facts' exist and question whether a 'scientific' approach can be used when dealing with human beings. Importantly Punch (2005:28) draws our attention to one important distinction which is that qualitative research not only uses non-numerical and unstructured data but also, typically, has research questions and methods which are more general at the start, and become more focused as the study progresses, yet there are occasions when qualitative researchers draw on quantitative techniques, and vice versa. It depends on what data the researcher requires (Mugenda and Mugenda 2003; Oso and Onen 2009). 
Classifying an approach as quantitative or qualitative, ethnographic, survey, action research or whatever, does not mean that once an approach has been selected, the researcher cannot move from the methods normally associated with that style. Each approach has its strengths and weaknesses, and each is particularly suitable for a particulars context (Bell 2010:6). The approach adopted and the methods of data collection selected will depend on the nature of the inquiry and the type of information required. I do not claim to do justice to any of the well-established styles of research; rather, I share with you some ideas about approaches one may wish to adopt in one's own investigation.

\section{Action Research and the Role of Practitioners}

Action research is an approach which is appropriate in any context when 'specific knowledge is required for a specific problem in a specific situation, or when a new approach is to be grafted on to an existing system' (Cohen and Menion 1994a: 194). It is not a method or a technique. As in all research, the methods selected for gathering information depend on the nature of the information required. It is applied research, carried out by practitioners who have themselves identified a need for change or improvement, sometimes with support from outside the institution; other times not. The aim is 'to arrive at recommendations for good practice that will tackle a problem or enhance the performance of the organization and individuals through changes to the rules and procedures within which they operate' (Denscombe 2010: 12).

Lomax (2007: 158, 169) provides a series of useful questions for action researchers under the headings of purpose, focus, relations, method and validation. Under the 'purpose' heading, she asks:

- Can I improve my practice so that it is more effective?

- Can I improve my understanding of this practice so as to make it more just?

- Can I use my knowledge and influence to improve the situation?

Under 'method', she asks whether the action researcher can collect 'rigorous data' which will provide evidence to support claims for action. These and similar questions can serve as a starting point for action research but when the investigation is finished and the findings have been considered by all participants, the job is not yet finished. The participants continue to review, evaluate and improve practice. The research involves 'feedback loops in which initial findings generate possibilities for change which are then implemented and evaluated as a prelude to further investigation' (Denscombe 2007: 123). It implies a 'continuous process of research' and 'the worth of the work is judged by the understanding of, and desirable change in, the practice that is achieved' (Brown and McIntyre 1981: 245).

There is nothing new about practitioners operating as researchers, but as in all 'insider' investigations, difficulties can arise if dearly held views and practices of some participants are challenged, as can happen if the research evidence appears to indicate that radical changes must take place if progress is to be made (Denscobe 2007:128). Of equal or perhaps even greater importance, is that before the research begins, everyone involved must know why the investigation is to take place, who will see the final report, and who will have responsibility for implementing any recommended changes. 


\section{Case Study}

The case study approach can be particularly appropriate for individual researchers because it provides an opportunity for one aspect of a problem to be studied, in some depth. Of course, not all case studies have to be completed in three months, or even three years. For example, Korman and Glennerster's (1990) study of what led to the closure of a large mental hospital took seven and a half years to complete. Yin reminds us that 'case studies have been done about decisions, about programmes, about the implementation process, and about organizational change. Beware these types of topic- none is easily defined in terms of the beginning or end point of the case'. He adds that 'the more a study contains specific propositions the more it will stay within reasonable limits' (Yin 1994: 137). This is a good piece of advice worthy following.

Case studies may be carried out to follow up and to put flesh on the bones of a survey. They can also precede a survey and be used as a means of identifying key issues which merit further investigation. However, the majority are carried out as free-standing exercises. Researchers identify an 'instance', which could be the introduction of a new way of working, the way an organization adapts to a new role, or any innovation or stage of development in an institution. Evidence has to be collected systematically, the relationship between variables studied (a variable being a characteristic or attribute) and the investigation methodically planned. Though observation and interviews are most frequently used, no method is excluded.

Critics of the case study approach draw attention to a number of problems and/or disadvantages. For example, some question the value of the study of single events and point out that it is difficult for researchers to cross-check information. Others express concern about the possibility of selective reporting and the resulting dangers of distortion. A major concern is that generalization is not always possible, though Denscombe (2007: 43) makes the point that 'the extent to which findings from the case study can be generalized to other examples in the class depends on how far the case study example is similar to others of its type'. He illustrates this point by drawing on the example of a case study of a small primary school. He writes: 'This means that the researcher must obtain data on the significant features (catchment area, the ethnic origins of the pupils and the amount of staff turnover) for primary schools in general, and then demonstrate where the case study example fits in relation to the overall picture' (2007: 43).

In his 1981 paper on the relative merits of the search for generalization and the study of single events, Bassey (1981) preferred to use the term 'relatability' rather than 'generalizability'. In this opinion 'an important criterion for judging the merit of a case study is the extent to which the details are sufficient and appropriate for a teacher working in a similar situation to relate his decision making to that described in the case study. The relatability of a case study is more important than its generalizability' (Ibid: 85). He considers that if case studies 'are carried out systematically and critically, if they are aimed at the improvement of education, if they are relatable, and if by publication of the findings they extend the boundaries of existing knowledge, then they are valid forms of educational research. (Ibid: 86). It suffices to observe that the pros and cons of case study will no doubt be debated in the future as they have been in the past. It is as well to be aware of the criticisms but, as I pointed out at the beginning of this section, case study can he an appropriate approach for individual researchers in any discipline because it provides an opportunity for one aspect of a problem to be studied in some depth. The researcher decides whether or not it suits his or her purpose. 


\section{Survey}

As Aldridge and Levine (2001: 5) point out, 'Each survey is unique. Therefore, lists of do's and don'ts are too inflexible. A solution to one survey may not work in another'. Moser and Kalton (1971: 1) agree that it would be pleasant to provide a straightforward definition of what is meant by a 'social survey' but make it clear that 'such a definition would have to be so general as to defeat its purpose, since the term and the methods associated with it are applied to an extraordinarily wide variety of investigations'.

The census is one example of a survey in which the same questions are asked of the selected population (the population being the group or category of individuals selected). It aims at covering 100 per cent of the population, but most surveys have less ambitious aims. In most cases, a survey will aim at obtaining information from a representative selection of the population and from that sample will then be able to present the findings as being representative of the population as a whole. Inevitably, there are problems in the survey method. Great care has to be taken to ensure that the sample production is truly representative. At a very simple level, that means ensuring that if the total population has 1000 men and 50 women, then the same proportion of men to women has to be selected. But that example grossly oversimplifies the method of drawing a representative sample and if the researcher decides to carry out a survey, he or she will need to consider what characteristics of the total population need to be represented in the sample to enable him or her to say with fair confidence that his or her sample is reasonably representative.

In surveys, all respondents are asked the same questions in, as far as possible, the same circumstances. Question wording is not as easy as it seems, and careful piloting is necessary to ensure that all questions mean the same to all respondents. Information can be gathered by means of self-completion questionnaires (as in the case of the census) or by an interviewer. Whichever method of information gathering is selected, the aim is to obtain answers to the same questions from a large number of individuals to enable the researcher not only to describe, but also to compare, to relate one characteristic to another and to demonstrate that certain features exist in certain categories ( Bell 2010:12). Surveys can provide answers to the questions 'What?', 'Where?', 'When?' and 'How?', but it is not so easy to find out 'Why?'Causal relationships can rarely, if ever, be proved by survey method. The main emphasis is on fact-finding, and if a survey is well structured and piloted, it can be a relatively cheap and quick way of obtaining data.

\section{Experimental Style}

Experiments may allow conclusions to be drawn about cause and effect, if the design is sound. However, large groups are needed if the many variations and ambiguities involved in human behaviour are to be controlled. Such large-scale experiments are expensive to set up and take a lot of time. Some tests which require only a few hours (for example, to test short-term memory or perception) can be very effective, but in claiming a causal relationship, great care needs to be taken to ensure that all possible causes have been considered.

It is worth observing at this juncture, that there can be ethical issues associated with experimental research. Permission to conduct the research must be obtained from the heads of institutions or units concerned and from the participants themselves. All must be fully informed about what is involved. Proposals may have to be considered by ethics committees and/or research committees in order to ensure that subjects of the research will 
not be harmed by it. Particularly if children are to be involved, it is especially important to seek permission to participate from parents (B ell 2010: 13).

Cohen et al. (2000:212) particularly object to the principle of 'manipulating' human beings. According to them:

"Notions of isolation and control of variables in order to establish causality may be appropriate for a laboratory, though whether, in fact, a social situation ever could become the antiseptic, artificial world of the laboratory or should become such a world is both an empirical and moral question .... Further, the ethical dilemmas of treating humans, as manipulable, controllable and inanimate are considerable. The foregoing observation not withstanding ethical issues have to be considered in all research, regardless of the context."

\section{Ethnography}

Brewer (2000:6) defines ethnography as: "The study of people in naturally occurring settings or 'fields' by methods of data collection which capture their social meanings and ordinary activities, involving the researcher participating directly in the setting, if not also the activities, in order to collect data in a systematic manner but without meaning being imposed on them externally. "Ethnographic researchers attempt to develop an understanding of how a culture works and, as Lutz (1986: 108) points out, many methods and techniques are used in that search.

"Participant observation, interview, mapping and charting, interaction analysis, study of historical records and current public documents, the use of demographic data, etc. But ethnography centres on the participant observation of a society or culture through a complete cycle of events that regularly occur as that society interacts with its environment".

Participant observation enables researchers, as far as is possible, to share the same experiences as the subjects, to understand better why they act in the way they do. However, it is time-consuming for researchers working especially on doctoral theses. The research has to be accepted by the individuals or groups being studied, and this can mean doing the same job, or living in the same environment and circumstances as the subjects for lengthy periods.

Time is not the only problem with this approach. As in case studies, critics point to the problem of representativeness. If the researcher is studying one group in depth over a period of time, who is to say that group is typical of other groups that may have the same title? Are nurses in one hospital (or even in one specialist area) necessarily representative of nurses in a similar hospital or specialist area in another part of the country? Are canteen workers in one type of organization likely to be typical of all canteen workers? Critics also refer to the problem of generalization but, as in the case study approach, if the study is well structured and carried out, and makes no claims which cannot be justified, it may well be relatable in a way that will enable members of similar groups to recognize problems and, possibly, to see ways of solving similar problems in their own group.

\section{Grounded Theory Approach}

The grounded theory approach to qualitative data analysis was developed by Glaser and Strauss (1967) in the 1960s during the course of a field observational study of the way 
hospital staff dealt with dying patients $(1965,1968)$. So what does it involve? According to Strauss (1987:5):

"The methodological thrust of the grounded theory approach to qualitative data analysis is toward the development of theory, without any particular commitment to specific kinds of data, lines of research, or theoretical interests. So, it is not really a specific method or technique. Rather it is a style of doing qualitative analysis that includes a number of distinct features, such as theoretical sampling, and certain methodological guidelines, such as the making of constant comparisons and the use of a coding paradigm, to ensure conceptual development and density."

Strauss (1987:21) defines theoretical sampling as: "sampling directed by the evolving theory; it is a sampling of incidents, events, activities, populations, etc. It is harnessed to the making of comparisons between and among those samples of activities, populations, etc.' (Ibid: 21). The theory is not pre-specified. It emerges as the research proceeds (hence 'theoretical' sampling). Over the years, there have been some adjustments to the original 1960s approach to grounded theory, but the principles remain much the same, which are that theory evolves during actual research by means of the analysis of the data.

Punch (2005:155) agrees but claims that 'grounded theory is not a theory at all. It is a method, an approach, a strategy whose purpose is to generate theory from data.... The theory will therefore be grounded in data. At first sight, this seems straightforward enough, but as Hayes (2000:184) puts it:

"The process of conducting grounded theory research isn't just a matter of looking at the data and developing a theory from it. Instead, it is what researchers call an iterative process that is, a cyclical process in which theoretical insights emerge or are discovered in the data, those insights are then tested to see how they can make sense of other parts of the data, which in turn produce their own theoretical insights, which are then tested again against the data, and so on."

Hayes (2000: 184) continues by reminding us that:

"The theory which is produced using a grounded theory analysis may sometimes be very context-specific, applying only in a relatively small number of situations; but because it is always grounded in data collected from the real world, it can serve as a very strong basis for further investigations, as well as being a research finding in its own right."

Most grounded theory researchers will begin with research questions but they do not start with a hypothesis; nor do they begin their investigation with thorough review of the literature relating to their topic. Instead they build up theory from their data and they do not wait until data are collected before they begin the analysis stage. Similarly, analysis takes place as the data are collected. The researcher examines the findings of an interview or of participant observation and then proceeds to the analysis of those findings before any data is collected. As the research proceeds, there will be more data collection and more analysis and so on until 'theoretical saturation' is reached, which is the stage at which 'further data produce no new theoretical development. Saturation is necessary to ensure that the theory is conceptually complete' (Punch 2005: 214-1).

Miles and Huberman (1994:62) have some reservations about the principle that coding and recording are over when the analysis appears to have run its course when all the 
incidents can be readily classified; when categories are 'saturated' and sufficient numbers of 'regularities' have emerged. They warn us to 'be careful here' because:

"Fieldwork understanding comes in layers; the longer we are in the environment, the more layers appear to surface and the choice of when to close down, when to go with a definitive coding system or definitive analysis can be painful. That choice may be dictated as much by time and budget constraints as on scientific grounds. When those constraints are relaxed, saturation can become a vanishing horizon-just another field trip away, then another..." (Ibid).

Glaser (1992) has also expressed some concern at the way grounded theory has developed over the years, in particular the development and use of computer-assisted code and retrieval software which claims to generate theory on grounded theory lines. He contends that more subtle procedures are required in order to tease out the layers of meaning which emerge, and this cannot be achieved by any narrow analytical procedures. New developments include the identification of more sophisticated criteria for grounded theory studies. For instance Charmaz (2008: 230-1) outlines four key criteria for considering the rigour and quality of a grounded theory study. These criteria provide a solid framework for - researchers in reviewing their own grounded theory study. The analysis of grounded theory data is rather complex. It requires the researcher to identify concepts, codes, categories and relationships in order to bring order to the data, and the time taken to become skilled at identifying and applying them is considerable. Nevertheless, the computer software can cope with the layers and the complexity pretty well. However, before one decides to commit oneself to a grounded theory approach, one must read as widely as possible. Additionally, one must be prepared to be advised before he or she finally decides how to proceed.

No doubt, stories are valuable sources of data. They are interesting and have been used for many years by historians, literary critics, management consultants, psychiatrists and other professionals. Narrative inquiry involves the collection and development of stories, either as a form of data collection or as a means of structuring a research project. Informants often speak in a story form during the interviews, and as the researcher, listening and attempting to understand, we hear their 'stories'. The research method can be described as narrative when data collection, interpretation and writing are considered a 'meaning-making' process with similar characteristics to stories (Gudmunsdottir 1996: 295). Gray (1998:12) adds that narrative inquiry can involve reflective autobiography, life story, or the inclusion of excerpts from participants' stories to illustrate a theme developed by the researcher. A narrative approach to inquiry is most appropriate when the researcher is interested in portraying intensely personal accounts of human experience. Narratives allow voice - to the researcher, the participants and to cultural groups - and in this sense they can have the ability to develop a decidedly political and powerful edge.

Stories are not merely used as a series of 'story boxes' piled on top of one another and with no particular structure or connecting theme. Such structures and themes are forms of narrative inquiry that involve an element of analysis and development of theme, dependent on the researcher's perspective. Accordingly,

"Stories share a basic structure. The power of a story is dependent on the storyteller's use of language to present an interpretation of personal experience. The skill of the narrative researcher lies in the ability to structure the interview data into a form which clearly presents a sense of a beginning, middle and an end. Even though the use of story 
as a research tool is a relatively new concept in the social sciences, historically story has been an accepted way of relating knowledge and developing self-knowledge. One of the major strengths of such a means of conducting inquiry is the ability to allow readers who do not share a cultural background similar to either the storyteller or the researcher to develop an understanding of notices and consequences of actions described within a story format. Narrative is a powerful and different way of knowing... "Data collection for narrative research requires the researcher to allow the storyteller to structure the conversations, with the researcher asking follow-up questions. So a narrative approach to the question of how mature-age undergraduates perceive their ability to cope with the experience of returning to study would involve extended, openended interviews with mature-aged students. This would allow the students to express their personal experience of the problems, frustrations and joys of returning to study. It might also involve similar 'conversations' with other stakeholders in their education perhaps family members; their tutors and lecturers - to provide a multiple perspective of the context of the education of mature-aged undergraduates" (Gray 1998:12-13).

He adds:

"Interviews are time-consuming and require the researcher to allow the storytellers to recount in their own way the experience of being (or teaching) a student. This may not emerge in the first interview. Until a trust relationship has developed between researcher and storyteller, it is highly unlikely that such intimate information will be shared. Such personal involvement with the researcher involves risks and particular ethical issues. The storytellers may decide they have revealed more of their feelings than they are prepared to share publicly and they may insist either on substantial editing or on withdrawing from the project" (Gray 1998:2).

Problems of this kind can arise in almost any kind of research, particularly those which are heavily dependent on interview data. However, the close relationship needed for narrative inquiry can make the researcher (and the storyteller) particularly vulnerable.

The fact that the narrative approach carries with it a number of potential difficulties, particularly for first-time researchers, and researchers operating within a particularly tight schedule, certainly does not mean that it should be disregarded when considering an appropriate approach to the topic of one's choice. Far from it - but as is the case with all research planning, it would be as well to discuss the issues fully with one's supervisor who (in case of a student) or expert (for non students) before deciding what to do, and if possible to try to find a supervisor who is experienced, or at least interested, in narrative inquiry.

\section{Which approach should be used?}

Classifying an approach as ethnographic, qualitative, experimental, or whatever, does not mean that once an approach has been selected, the researcher cannot move from the methods normally associated with that style. But understanding the major advantages and disadvantages of each approach is likely to help one to select the most appropriate methodology for the task in hand. This paper covers only the principles associated with different styles or approaches to research. What, however, is the nexus between research and quality assurance? This question constitutes the contents of the next section. 


\section{Research and Quality Assurance at Uganda Martyrs University}

According to Standa (2007:21), universities should have well defined policies for creating an environment that enables faculty to carryout research. Accordingly, each Department should have an effective research plan with suitable implementation, evaluation and feedback mechanisms. In the same vein, research directorates in universities should collect information on the participation of faculty in research activity, research income from different sources and ways and means of enhancing the research skills of faculty. These are areas where the Directorate of Research and the Directorate of Quality Assurance at Uganda Martyrs University (UMU) strike a responsive chord.

It is gratifying to note that UMU meets Standa's prescription above. UMU's Directorate of Research operates within the university's research policy (UMU Research Policy, 2010: 1-19). According to the policy, "Research is the key to creativity, innovation quality education (my emphasis) and progressive advancement of knowledge, which culminates into academic competency and shared wisdom". And in tandem with my earlier thesis, UMU's research policy in part states that "As a central tenet of the University mission, research shall complement and invigorate teaching as well as support the preservation, dissemination and advancement of knowledge for the betterment of society on the basis of good scholarship" (UMU Research Policy 2010:5). In all these, quality becomes imperative. Instructively, the university's vision is that of realizing "High quality (my emphasis) research that addresses community needs and meets international expectations "(UMU Research Policy 2010:5). In order to reinforce its vision, the policy statement is categorical that:

"Research is part of UMU's three - track mandate of teaching, research and community service. Indeed, the University's research activities touch on all three categories of research relevant to a higher learning institution, namely, student research, staff research and participatory research. It also touches on all the three types of research, namely basic, applied and participatory" (UMU Research Policy, 2010:6).

I hasten to reiterate that my order of ranking the three - track mandate puts research on top because teaching must be based on new knowledge generated by research whose findings have been disseminated in reputable books, journals, monographs and other credible outlets. Similarly, community service must be based on or linked to research. And in the entire three track mandate, quality must be paramount. This is where the Quality Assurance Directorate touches base with the Directorate of Research.

In as far as policy guidelines are concerned, and I quote them in full because of their importance and relevance to quality assurance,

"Research at UMU shall be both basic and applied. All types of research may be demanded according to existing constraints. Basic research shall refer to either pure basic research or strategic basic research. Pure basic research shall be experimental or theoretical work undertaken to acquire new knowledge without looking for long term benefits other than the advancement of knowledge. Strategic basic research shall be experimental and theoretical work undertaken to acquire new knowledge directed into specified broad areas with expectation of useful discoveries. It shall provide broad based knowledge that is necessary for the solution of recognized practical problems.

"Applied research shall be original work undertaken primarily to acquire new knowledge with a specific application in mind. It shall be undertaken either to 
determine possible use for the findings of basic research or to determine new ways of achieving some objectives.

"Experimental development shall be systematic work, using knowledge gained from research or practical experience that is directed to producing new materials, products or devices; installing new processes, systems and services; or improving this that are already produced or installed.

"Overall, Uganda Martyrs University shall invest and give more emphasis to applied research in terms of resources and time allocated" (UMU Research Policy 2010:6)".

The university is certainly right in preferring applied research to the other types of research. No doubt, a developing country like Uganda needs applied research to tackle its numerous developmental, scientific and technological challenges. However, the concept of "original work" should not necessarily mean "virgin" areas of research; originality should be extended to interpretation and even re-interpretation of existing knowledge of findings. This is especially true of the social sciences and humanities. In the same vein, pure basic research would not mean much if it does not yield not just new knowledge, but rather new relevant (my emphasis) knowledge that will benefit society; that is why, indeed, its findings should be subjected to verification via applied research. That, too, is why I prefer strategic basic research although it seems to be rather expensive for a university like UMU that operates on limited resources. However, in collaboration with better endowed universities and other organizations especially in the developed world, it can be successfully conducted.

In all types of research, quality is paramount. This entails high international standards. Sub-standard research would undermine the credibility of not just the researcher, but the entire university. In this regard, the Directorate of Quality Assurance would partner with the Directorate of Research to ensure high quality research which if achieved, would contribute towards ranking UMU.

But what, essentially, are quality and quality assurance? How far true is it that the concept of quality assurance is not only new to African Universities, but it also does not apply to them? According to Lejeune (2005:31), when people talk about quality assurance, they often mean something that is not or something it should not be. He continues: "For example, to say that QA stands for a better life of the members employed by higher institutions or that QA stands for material standards of an infrastructure are partly true but very incomplete" (Ibid).

According to Middlehurts and Campbell (2004:90-91):

"Quality Assurance is an important part of academic professionalism. It is also a key mechanism for building institutional reputation or brand in a competitive local and global arena and a necessary foundation for consumer protection. Across the world, it is part of the armoury used by governments to increase, widen or control participation in the face of rising demand for higher education as a public good or tradable commodity. Quality assurance is also fundamental to the security of qualifications and the mobility of professionals. Without effective and appropriate quality assurance policies and practices, aspirations towards knowledge economics, lifelong learning, community development and social inclusion cannot be fully realized. It is for these reasons that quality assurance is receiving increasing attention at all levels" 
There is no general consensus on the concept of quality as such. An absolution definition of quality does not exist because just like beauty, quality is in the eyes of the beholder. And whereas the general concept of quality is a difficult one in itself, quality in higher education is much more complex and it is not often clear what the 'product' is and who the 'client' is. In my opinion, though, in terms of research, the 'product' should be quality research that solves society's problems. The 'client', therefore, is society.

According to the Inter-University Council for East Africa (IUCEA) (2010:4), absolute or objective quality does not exist. Quality, therefore, becomes a matter of negotiation between the academic institution and the stakeholders. In this process, all stake holders need to formulate, as clearly as possible, their requirements. In the case of research, high standards, discipline, integrity and honesty, inter alia, are the requirements, in my opinion. The university or faculty, as the eventual suppliers of service, must try to reconcile all these different wishes and requirements. This is where the Directorate of Quality Assurance and the Directorate of Research are relevant.

In the Constitution of Ugandan Universities Quality Assurance Forum (UUQAF) (2011:2), quality refers to 'fitness for purpose'; meeting or conforming to generally accepted standards as defined by an institution, quality assurance bodies and appropriate academic and professional communities. This definition tallies with the one provided by the IUCEA. Having attempted to define the concept of quality, it is proper and fitting to equally try to define quality assurance.

According to the constitution of UUQAF (2011:2), quality assurance is a planned and systematic review process of an institution or programme to determine whether or not acceptable standards of education, scholarship and infrastructure are being met, maintained and enhanced. Similarly, according to National Council for Higher Education (NCHE 2006:3), quality assurance is the mechanism put in place to guarantee that the Education is "fit for the purpose", i.e., is good.

Thus quality assurance involves quality control without which high standards will not be achieved. Quality assurance is cross-cutting; it involves all spheres of life, research inclusive, and it is a universal concept. It may be a relatively new concept in Africa but it is certainly relevant to African universities as well. Quality assurance, therefore, involves excelling in whatever one does, research inclusive.

In this regard, UMU can excel in research and be at the top. However, the question is "do we want to be there?" if so, what can we do? How can we improve the situation ourselves? In a nutshell, quality assurance helps to provide the answers. Quality assurance, therefore, becomes absolutely necessary because as Lejeune (2005:35) counsels, "without it we will be marginalized and few will be interested in real collaboration with us." Indeed, in a globalized world where barriers and frontiers seem to melt away, there is no way we can sit back and ignore the trends of the day because we are now living in a "global village" characterized by a global knowledge industry which dictates that we become researchers /scholars without borders. In this enterprise, crafting, implementing and maintaining high quality in research become imperative.

At this juncture, I proceed to discuss the other areas of partnership between the Directorate of Research and the Directorate of Quality Assurance. These can be identified in the processes of writing research reports as governed by ethical issues. 
Uganda Martyrs University research policy has a very strong statement regarding ethical issues and misconduct that are uphold by the general scholarly community in conducting research. Since it has a bearing on quality assurance, I quote it at length:

"The following shall constitute research misconduct:

- Failure to report known incidents of serious research misconduct.

- Covering up or otherwise failing to report major offences of research known to oneself; and /or

- Retaliation: Taking punitive action against an individual for having reported alleged major research offences.

- Research misconduct does not include honest error or honest differences in interpretations or judgments of data. Serious misconduct shall be distinguished from honest error and differences of interpretation inherent in any scientific and creative process and which are normally corrected through further research and scholarship.

- Te deliberate development of biological or other agents for purposes of terrorism.

- Failure to report (misprision) laboratory accidents.

"The following practices shall be considered as a breach of ethics and researchers perpetrating them subjected to strict disciplinary action:

- Fabrication of data: Dishonesty in reporting results, ranging from fabrication of data, improper adjustment of results, and gross negligence in collecting or analyzing data, to selective reporting or omission of data for deceptive purposes;

- Falsification of research: Deliberately misrepresenting research, including the progress of research, making exaggerated claims of the significance of research results, falsely claiming priority by wilfully ignoring prior relevant reports in research literature.

- Plagiarism: Taking credit for someone else's work and ideas, stealing other's results or methods, omitting acknowledgement of significant contribution(s) received from others, copying the writing of others without proper acknowledgement, or otherwise falsely taking credit for the work and ideas of others.

- Failure to acknowledge: Wilfully ignoring and failing to acknowledge the source of materials used in laboratory research.

- Abuse of confidentiality: taking or releasing ideas and data that were shared with the legitimate expectation of confidentiality (e.g. use of confidential results without permission of other researchers or previous employers), stealing ideas from others' grant proposals, award applications, or manuscripts.

- Dishonesty in publication: Knowingly publishing material that will mislead readers (e.g. misrepresenting data, particularly its originality, misrepresenting research progress, adding the names of other authors without their permissions, or including honorary authorships or excluding a major collaborator as co- author of the publication).

- Property violations: stealing or destroying property of others, such as research papers, supplies, equipment or products of research.

- Misuse of Funds: Failure to spend research funds in ways consistent with the goals stated in the relevant contract documents and /or failure to maintain clear and proper records of expenditures.

- Mistreatment of human research subjects: Failure to obtain informed consent of research informants /clinical trial patients, failure to protect the rights of informants 
regarding their privacy and to protect the research subject's anonymity and the confidentiality of information sources".

In connection to the foregoing quotation, the Directorate of Quality Assurance takes responsibility for evaluating the quality of research vis-à-vis what kind of research, particularly applied or action - based research which is geared towards solving societal problems, be it for a degree or for other eclectic reasons. In this regard, the Directorate of Quality Assurance partners with the Directorate of Research to ensure that permission or authorization is attained in order to conduct research. The Directorate of Quality Assurance is also interested in seeing that researchers abide by the three major areas of ethical concern: First, ethics of data collection and analysis. Second, treatment of witnesses/ participants/ respondents. Third, ethics of responsibility to society. In this endeavour, the Directorate of Quality Assurance becomes a watchdog in ensuring that the researcher gets informed consent of the participants that interviews will be treated as confidentially and anonymously as possible unless they consent to the contrary. The researcher has to ensure that no harm- whether physical or psychological, deliberately accrues to individuals, groups and /or society.

In the process of data analysis, quality becomes imperative. Thus, sources of information have to be acknowledged whether through quotation or paraphrasing. This is for the purpose of avoiding the vice of plagiarism as spelt out in the UMU research policy document. The researcher has to be critical in terms of value addition. That is, issues being addressed have to be geared towards positively transforming society presently and in future. This is also connected to the need for originality in terms of either coming up with new and relevant knowledge or critiquing old, outdated or moribund ideas.

Quality assurance concerns also hinge on mobilization of resources for research which is not only high level but wide in focus in terms of being either inter -disciplinary or transdisciplinary. I appreciate that the university, via its Research Directorate, funds some research projects. However, the funding is inadequate and research overheads are high in terms of what the university is supposed to obtain. This, therefore, calls for sourcing outside funding of research activities with the view to providing a sound financial base, acquiring the necessary facilities such as up-to-date books, journals, laboratories, state-ofthe art library, computers and other equipments that are required for quality research. In this regard, the Directorate of Quality Assurance intends to partner with the Directorate of research in writing joint proposals for possible funding by well endowed universities and Research institutions especially from the northern hemisphere.

The question of supervision is also very critical in ensuring quality research especially at the graduate level. Many Departments still lack adequate doctoral degree holders to supervise masters and doctoral candidates and to guide research. In many instances, masters degree holders, some of whom themselves did not write theses during their training, are supervising masters candidates to the chagrin of the latter. To say the least, this practice has the tendency of compromising standards and, therefore, calls for an urgent intervention. Such intervention is four-fold. First, encouraging and supporting doctoral studies. Second, suspending master's programmes in those Departments with no $\mathrm{PhD}$. holders to supervise graduate students until they attain the capacity to run such programmes. Third, pairing masters and Ph. D. holders in the supervision exercise where by the former would be under some kind of "internship" under the watchful eyes and stewardship of the latter Fourth, involving Ph.D. holders from other universities within 
and outside Uganda In the supervision and research domains. Such intervention also requires writing joint proposals and crafting Memoranda of Understanding (MOU) which would, inter-alia, take care of the University's training needs at the graduate level via faculty and student exchange, sponsorship to pursue graduate studies abroad or through sandwich arrangements. The Directorate of Quality Assurance is willing to partner with the Directorate of Research in order to alleviate the situation.

Research requires a conducive, encouraging and enabling environment. No doubt, the university has some of the best brains in Uganda. However, in terms of remuneration, can the university retain them? Yes, if the terms and conditions of service were significantly improved. No, if the status quo is maintained, for the beautiful environment and friendly weather alone cannot work out the trick. But to be fair to the university, the burden also lies squarely on the shoulders of faculty. They should not simply wait and see what the university can do for them; rather, they too, should do something for themselves and for the University. This calls for writing fundable research proposals which the university can help market, a kind of win - win - situation rather than a zero - sum - game where the winner takes all. The Directorate of Quality Assurance is eager to participate in this venture, for this is the trend that the university in the twenty first century is supposed to take.

Dissemination of research findings is yet another locus where quality assurance resides. Both Directorates have a stake in it. Without appearing to flog a dead horse, it is imperative to state that whatever data are gathered in the field need to be analyzed or interpreted and disseminated to the stakeholders in a professional manner. The issue of relevance to society needs to be addressed in the process of dissemination of research findings. This exercise needs to take care of high standards which include meticulous quality control which includes peer reviewing manuscripts before they are published in reputable international journals and books by credible publishers. This should answer the question usually asked by scholars/researchers. The other question usually asked is how do we know that a book or journal meets international standards? In case of a book, it must have the acronym ISBN- which in full stands for International Standards Book Number. In case of a journal, it must have the acronym ISSN-which in full stands for International Standard Series Number. This means that the book and / or journal has been refereed or peer - reviewed. Technically, therefore, any book without ISNB and journal without ISSN has not yet been published and as such, cannot be quoted in one's curriculum vitae as published works; neither can they qualify a scholar for promotion.

Another question frequently asked is: what is a credible publisher? In my opinion, a credible publisher is one which commands national and international respect through publishing high quality of manuscripts which have been rigorously vetted by renown peers in given disciplines. It can be a national publishing house like, in the case of Uganda, Fountain Publishers, which has established a niche in publishing not only in the country, but in the entire Great Lakes Region of Africa. It can be a university press like Uganda Martyrs University Book Series, University of Nairobi Press, University of California Press, Cambridge University Press, Oxford University Press, etc. It can be a foundation or think tank press like the Jomo Kennyatta Foundation in Kenya, James Currey, Zed Press and Routledge in London or Progress Publishers in Moscow.

It is gratifying to note that UMU meets these criteria. The Directorate of Research publishes, on UMU's behalf, the Journal of Science and Sustainable Development (ISSN 2070-1748), Mtafiti Mwafrika (African Researcher)ISSN 1607-0011, Journal of 
Development Studies ISSN 2079- 4843 published by the Institute of Ethics and Development Studies. These Journals are listed in African Journals Online and syndicated in several major databases of scholarly work, which authenticate the internationalism of the journals.

\section{Conclusion}

Research is immensely critical in benchmarking development from the local, national, regional, continental and global points of view. But it is not just research per se; it has to be quality research - hence the nexus between research and quality assurance. Research is a corner stone for quality assurance and so is quality assurance a cornerstone for research a kind of symbiotic relationship between the two concepts-the former being a fairly new concept in Africa although it is universal in character.

In conducting research, questions relating to method and methodology need to be clearly understood. Rather than presuming that they can be used interchangeably, they are different as has been demonstrated in the paper.

There are numerous approaches in conducting research. There are no tight rules in the researcher using them. What is clear is that any of the approaches can be used either singularly or in combination with other approaches. This is at the discretion of the researcher. Nevertheless, some disciplines are particular about certain approaches. However, in an interdisciplinary or trans- disciplinary research, it is advisable to use bilateral or multilateral approaches.

The nexus between research and quality assurance lies in the provisions of quality and its control. Essentially, this involves evaluation of research quality in regard to the type of research, particularly applied research, taking into consideration ethical concerns that must be jealously guarded.

The other areas of concern involve safeguarding against plagiarism by emphasizing originality in data collection and interpretation leading to logical conclusions and dissemination of research findings. In the pursuit of original research, resource mobilization that culminates into high calibre training of faculty, their favourable remuneration and retention becomes a vital yardstick for quality assurance in higher educational institutions in the era of current globalization.

\section{Editor's Note}

An earlier draft of this paper was presented as a keynote address at the Fourth Annual Uganda Martyrs University Research Conference held at Emmanuel Cardinal Wamala Auditorium, Uganda Martyrs University, Nkozi, November, 2011. The paper has since been subjected to peer review and, subsequently, revised.

\section{References}

Aldridge, A. and Levine, K. (2001) Surveying the Social World: Principles and Practice in Survey Research. Buckingham: Open University Press.

Bassey, M. (1981) 'Pedagogic research: on the relative merits of the search for generalization and study of single events', Oxford Review of Education, 7 (1): 73-93. 
Bell, J. (2010) Doing your Research Project: A guide for first - time researchers in education, health and social science. Fifth edition. Berkshire, England: Open University Press.

Brewer, J. D. (2000) Ethnography. Buckingham: Open University Press.

Brown, S. and McIntyre, D. (1981) 'An action- research approach to innovation in centralized educational systems', European Journal of Science Education, 3 (3): 243258.

Charmaz, K. (2008) 'Grounded theory in the $21^{\text {st }}$ Century: applications for advancing social justice', in N.K. Denzin and Y.S. Lincoln (Eds) Strategies of Qualitative Inquiry, third edition. Thousand Oaks, California: Sage Publication.

Cohen, L. and Manion, L. (1994a) Research Methods in Education, fourth edition. London: Routledge.

Cohen, L. and Manion, L. (1994b) 'case studies', in L. Cohen and L. Manion, Research Methods in Education, fifth edition. London: Routledge Falmer.

Cohen, L. Manion L. and Morrison, K. (2000) Research Methods in Education, fifth edition. London and New York: Routledge Falmer.

Denscombe, M. (2010) Ground Rules for Good Research: Guidelines for Good Practice, second edition. Buckingham: Open University Press.

Glaser, B.G. (1992) Basics of Ground Theory Analysis. Mill Valley, California: Sociology Press.

Glaser, B.G. and Strauss, A. L. (1967) The Discovery of Grounded Theory: Strategies for Qualitative Research. New York: Aldine.

Hall, B. (1977), 'Participatory research: expanding the base of analysis', International Development Review, 4.

Hayes, N. (2000) Doing Psychological Research: Gathering and Analyzing Data. Buckingham: Open University Press.

Korman, N. and Glennester, H. (1990) Hospital Closure: A Political and Economic Study. Buckingham: Open University Press.

Lejeune, M. (2005) 'Uganda universities: the challenge of quality', The Uganda Higher Education Review: Journal of the National Council for Higher Education, 2(2): 31-37.

Lutz, F.W. (1986) 'Ethnography: the holistic approach to understanding schooling', in M. Hamersley (Ed.) Controversies in Classroom Research Milton Keynes: Open University Press.

Middlehurts, R. and Campbell, C. (2004) 'quality assurance and borderless higher education: finding pathways through the maze,' in Mapping Borderless Higher Education. Policy, Markets and Competition. London: Association of Commonwealth Universities.

Miles, M.B. and Huberman, A.M. (1994) Quality Data Analysis, second edition. Thousand Oaks, California: Sage Publications.

Mitroff, I. and Kilman, R. (1981) 'Methodological approaches to social science', in P. Reason and J. Rowan (eds) Human Inquiry: A Source Book of New Paradigm Research. New York: Wiley.

Mitroff, I. and Sagasti, F. (1993) 'Epistemology as general systems theory: an approach to the design of complex decision - making experiments'. Philosophy of the Social Sciences, 3.

Moser, C.A. and Kalton, G. (1971) Survey Methods in Social Investigation, second edition, London: Heinemann. 
Mugenda, O. and Muganda, A.G. (2003) Research Methods: Qualitative and Quantitative Approaches. Nairobi: Acts Press.

Murty, K. S. (1995) Handbook of Research Methodology in History. New Delhi: Sterling Publishers.

Oso, W. Y. and Onen, D. (2009) A General Guide to Writing Research Proposal and Report - A Handbookfor Beginning Researchers. Nairobi: Jomo Kenyatta Foundation.

Punch, K. F. (2005) Introduction to Social Research: Quantitative and Qualitative Approaches, second edition. London: Sage.

Rakitov, A. (1989) The Principles of Philosophy. Moscow: Progress Publishers.

Schwartz, P. and Ogilvy, N. (1979) The Emergent Paradigm: Changing Patterns of Thought and Belief. Mendon Park: SRI International.

Stand, E. (2007) 'Institutional autonomy and academic freedom', The Uganda Higher Education Review: Journal of the National Council for Higher Education, 4 (1).

Strauss, A. L. (1987) Qualitative Analysis for Social Scientists. Cambridge: Cambridge University Press.

The Constitution of Ugandan Universities Quality Assurance Forum (UUQAF) (2011). Kampala: Unpublished: 1:15.

The Inter- University Council for East Africa (IUCEA) (2010), A Road Mark to Quality: Hand book for Quality Assurance in Higher Education Volume I- Guidelines for Self Assessment at Programme Level. Kampala: The IUCA / DAAD.

The National Council for Higher Education (2006), Quality Assurance Framework for Uganda Universities. Kampala: NCHE.

UMU (2010) 'Uganda Martyrs University Research Policy', Unpublished. Directorate of Research, Uganda Martyrs University: 1-19.

Yin, R.K. (1994) 'Designing single and multiple - case studies,' in N. Bennett, R. Glatter and R. Levacic' (eds) Educational Management through Research and Consultancy, London: Paul Chapman Publishing.

\section{Author Biography}

Pontian G. Okoth $(\mathrm{PhD})$ is a Professor of History and International Relations at the Department of Peace and Conflict Studies, Masinde Muliro University of Science and Technology, Kenya. Formerly, he was the Director of Quality Assurance at Uganda Martyrs University and a Professor at the East African School of Diplomacy, Governance and International Studies. 